Emir. J. Agric. Sci. 2003. 15 (2): 42-50

http://www.cfs.uaeu.ac.ae/research/ejas.html

\title{
Evaluation of nutritional status of United Arab Emirates University female students
}

\author{
Abdelhamid Kerkadi \\ Department of Nutrition and Health, College of Food Systems, \\ United Arab Emirates University, Al-Ain, UAE
}

\begin{abstract}
The purpose of this study was to evaluate the prevalence of underweight, overweight, and obesity, the widespread diseases and the food consumption patterns among UAE university female students. Height and weight were measured in a sample of 400 female students aged 18-25 years. A self administrated questionnaire addressing food habits, food consumption, sports practice and disease states was completed by each student. Body Mass Index (BMI) was calculated for each subject. WHO classification was used for defining underweight $(\mathrm{BMI}<18.5$ $\left.\mathrm{kg} / \mathrm{m}^{2}\right)$, overweight $\left(\mathrm{BMI}=25-29.9 \mathrm{~kg} / \mathrm{m}^{2}\right)$ and obesity $\left(\mathrm{BMI}>30 \mathrm{~kg} / \mathrm{m}^{2}\right)$. The results indicate that the prevalence of underweight, overweight and obesity were $13 \%, 19.4 \%$ and $6.7 \%$ respectively. The widespread self reported diseases in descending order of magnitude were anemia (19\%), food allergy (4.8\%), hypertension (2.8\%) and diabetes $(1 \%) .62 \%$ of the students did not practice any kind of sports. Food habits results showed that $44.8 \%$ of the respondents did not take breakfast, $34.9 \%$ took fast food at least once a day, and $52,3 \%$ took only 1 to 2 meals /day. Results of food consumption showed that $54.4 \%$ of the students consumed a diet low in cereals, $51.5 \%$ consumed a diet low in vegetables, $49.5 \%$ consumed a diet low in fruits, and $46.7 \%$ of the students consumed a diet high in fat. Results also noted a statistically significant association between consumption of cereals and fruits and BMI classes. Therefore, there is a necessity to develop a nutrition education program for UAE students in order to help them change their food habits and avoid the negative health consequences of being overweight or underweight.
\end{abstract}

Keys words: Obesity, Underweight, Food habits.

قيم الحالة النذوبة لمالبلت جلمعة الإمارت العربية المتحة عبد الحميدكركاي

قعم الثغنية والمحة، كلية ظام الأغنية، جلمعة الإمارل العربية المتحة، العن، الإمارل العربية المتحة

ملخص: الهف من هذه الدرلسة هو ققييم نسبة انتشار النحافة وزيادة الوزن وللسمنة بينطالبت جلمعة الإم ارات العربي ة

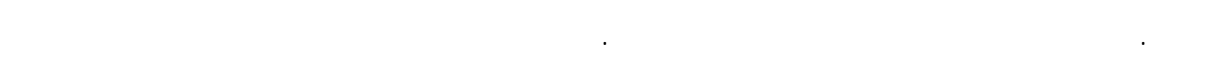

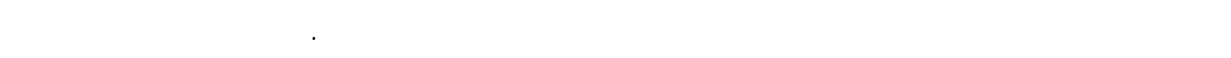

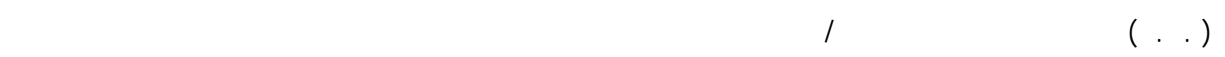

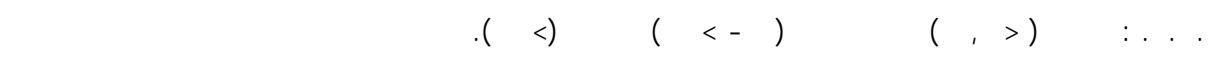

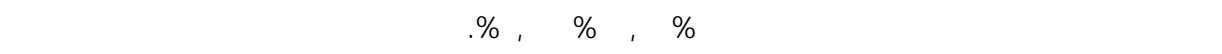

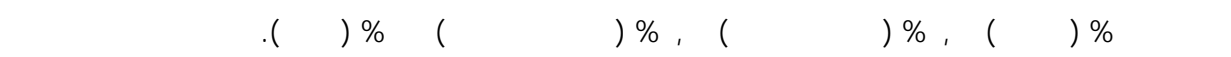

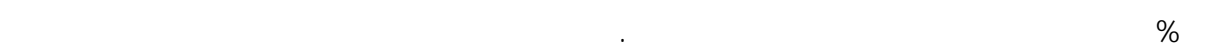

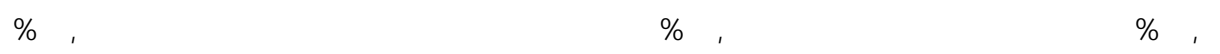

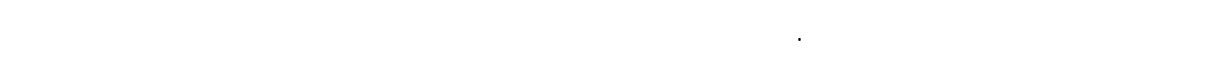

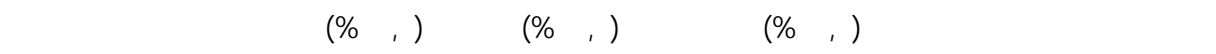
أع 7,V) الغذائية وتخفف مدى انتشار زياة الوزن والنحافة بين الطالبت في جلمعة الإمارات العربية المتحدة. 


\section{Introduction}

Obesity is currently an escalating epidemic that affects many countries in the world including the Arabian Gulf region (Al Isa, 1995; 1999; Al Shammari et al., 1994; Al Mahroos and Al-Roomi, 1999: El Mugamer et al., 1995: AlAwadi and Amine, 1989), where this condition is responsible for increasing death rates annually. It is a major contributor to precipitating or aggravating chronic diseases (Guo and Chumlea, 1999), including type 2 diabetes mellitus, coronary heart disease, and hypertension. Several studies have shown an increased prevalence and incidence of type 2 diabetes in obese persons in the Arabian peninsula (Moussa et al, 1999; Al-Mahroos and McKeigue, 1998; Al-Nuaim et al., 1996; El Mugamer et al., 1995).

The prevalence of obesity, especially among females, in Arabian Gulf countries has increased dramatically during the past decades (Musaiger, 1987). This increase in the prevalence of obesity is due to life style changes (physical inactivity, leisure and modernization) and nutrition transition which are in relation with changing economic, social, and health factors. It is well known that Arabian Gulf countries have moved toward the higher fat and higher refined carbohydrates Western diet (Popkin, 2001). Major dietary changes include a large increase in the consumption of fat and added sugar in the diet, often a marked increase in animal food products contrasted with a fall in total cereal intake, and vegetable and fruits consumption.

The United Arab Emirates enjoys a high capita income which is considered among the highest in the world. The country has undergone significant changes in nutritional and life style habits, similar to those in other Arabian Gulf countries, over the last three decades. Such changes are expected to have an impact on the magnitude of chronic diseases including obesity. 71\% of married women and $56 \%$ of married men were found obese (Musaiger and Al-Ansari, 1992). These percentages are higher than those reported in other Gulf countries, indicating that obesity is a public health problem in the United Arab Emirates. Other studies have reported a high prevalence of overweight and obesity among UAE University female students (Musaiger and Radwan, 1995; Amine and Samy, 1996).

In the present study, we examine the prevalence of underweight, overweight, obesity, and possible associated factors (food habits and physical activity) among female students in the UAE University.

\section{Materials and Methods}

Subjects

The study consisted of 400 female students aged between 18-25 years $(2.5 \%$ of the total females students enrolled in the United Arab Emirates University in 2001/2002). Students were recruited by announcement at the hostels and at the different colleges. Subjects were assembled in the dietetic clinic of the Department of Nutrition and Health at UAE University where they were interviewed by trained graduate students and their weights and heights were measured. 
Anthropometric data

Standard techniques were adopted for obtaining anthropometric measurements. Subjects were weighed in light clothes and with no shoes using a Seca scale to the nearest $0.1 \mathrm{~kg}$. Height was measured to the nearest $0.1 \mathrm{~cm}$ using a wall- mounted stadiometer.

The Body Mass Index (BMI) was determined from the ratio of weight to height squared $\left(\mathrm{kg} / \mathrm{m}^{2}\right)$, and students were categorized according to the WHO classification. [Underweight (BMI $<18.5)$; Normal weight $(19<\mathrm{BMI}>24.9)$; overweight $(25<\mathrm{BMI}>29.9)$ and obese (BMI>30)].

Food and life style questionnaire

Each student was asked to complete a questionnaire which addressed questions related to food consumption pattern, food habits and physical activity (nature and duration).

Statistical analysis

All statistical analysis was conducted using SPSS (11.0) for Windows. In addition to descriptive statistics, the Chi square test was used to assess association between categorical variables. A $P$ value $\leq 0.05$ was used as the criterion of statistical significance. The percentage of the study population in different BMI categories was calculated for the total sample and stratified by age group.

\section{Results}

Table 1 shows the sample in terms of weight, height and BMI. Mean weight and height for the different age groups were $57.9 \pm 0.6 \mathrm{~kg}$ and $158.7 \pm 0.3 \mathrm{~cm}$ respectively; BMI was $22.9 \pm 0.2 \mathrm{~kg} / \mathrm{m}^{2}$. Results show that the mean weight and height increased gradually with age reaching the maximum between 20-21 years old. We noted a significantly difference for weight and BMI according to age.

The distribution of female students by age and BMI is illustrated in table 2 . The results show that $6.7 \%$ were obese, $19.4 \%$ were overweight, $60.9 \%$ were normal, and $13 \%$ were underweight. The prevalence of overweight increased with age group and reached its highest rate (47.6\%) among students aged between $20-21$ years and decreased to $34.7 \%$ among students older than 22 years. The prevalence of obesity was least $(11.5 \%)$ among young students aged between 18 19 years old while the highest rate $(46.2 \%)$ was observed in the group 2021 years. The opposite trend was noted with underweight which was most common among young students.

Table 3 shows factors associated with BMI. Results indicate that $45 \%$ of female students skipped breakfast. $62 . \%$ of students did not practice sport, 38\% practiced a mild sport (Walk). $6.8 \%$ of them were obese. $34.9 \%$ of students reported that they consumed fast food at least once a week, and $52.3 \%$ took only 1 to 2 meals /day. It is noted that the highest prevalence of underweight, overweight and obesity was observed among students living in the hostels compared to students living at home. We have to note that the factor age was found to be significantly associated with BMI classes. 
Abdelhamid Kerkadi

Table 1. Mean for weight, height and BMI of UAEU female students

\begin{tabular}{lccc}
\hline Age & $\begin{array}{c}\text { Height } \\
\mathbf{( c m )}\end{array}$ & $\begin{array}{c}\text { Weight } \\
\mathbf{( k g )}\end{array}$ & $\begin{array}{c}\mathbf{B M I} \\
\mathbf{( k g / \mathbf { m } ^ { 2 } )}\end{array}$ \\
\hline $18-19$ & $157.9 \pm 0.6$ & $55.1 \pm 1.1$ & $22.1 \pm 0.4$ \\
$20-21$ & $159.3 \pm 0.5$ & $58.9 \pm 0.9^{*}$ & $23.1 \pm 0.3^{*}$ \\
$\geq 22$ & $157.9 \pm 0.5$ & $58.9 \pm 1.3^{*}$ & $23.5 \pm 0.5^{*}$ \\
Total & $158.7 \pm 0.3$ & $57.9 \pm 0.6$ & $22.9 \pm 0.2$ \\
\hline
\end{tabular}

Results are expressed as mean $\pm \mathrm{SE}$

* Significantly different from group 18-19 years old at $\mathrm{P} \leq 0.05$

Table 2. Distribution of female students according to BMI and age

\begin{tabular}{llllll}
\hline \multicolumn{1}{c}{ BMI } & $\begin{array}{c}\text { Underweight } \\
\mathbf{N ~ ( \% )}\end{array}$ & $\begin{array}{c}\text { Normal } \\
\mathbf{N ~ ( \% )}\end{array}$ & $\begin{array}{c}\text { Overweight } \\
\mathbf{N}(\mathbf{\%})\end{array}$ & $\begin{array}{c}\text { Obese } \\
\mathbf{N}(\%)\end{array}$ & $\begin{array}{c}\text { Total } \\
\mathbf{N}(\%)\end{array}$ \\
\hline $18-19$ & $19(38 \%)$ & $59(25.1 \%)$ & $14(18.7 \%)$ & $3(11.5 \%)$ & $95(24.6 \%)$ \\
$20-21$ & $19(38 \%)$ & $108(46 \%)$ & $35(46.7 \%)$ & $12(46.2 \%)$ & $174(45.1 \%)$ \\
$\geq 22$ & $12(24 \%)$ & $68(28.9 \%)$ & $26(34.7 \%)$ & $11(42.3 \%)$ & $117(30.3 \%)$ \\
Total & $50(13 \%)$ & $235(60.9 \%)$ & $75(19.4 \%)$ & $26(6.7 \%)$ & $386(100 \%)$ \\
\hline
\end{tabular}

Table 3. Factors associated with BMI classes among UAEU female students

\begin{tabular}{|c|c|c|c|c|c|c|c|c|c|c|c|}
\hline \multirow{2}{*}{$\begin{array}{l}\text { BMI classes } \\
\text { Factors }\end{array}$} & \multicolumn{2}{|c|}{ Underweight } & \multicolumn{2}{|c|}{ Normal } & \multicolumn{2}{|c|}{ Overweight } & \multicolumn{2}{|c|}{ Obese } & \multicolumn{2}{|c|}{ Total } & \multirow[t]{2}{*}{$\begin{array}{c}\text { Chi } \\
\text { Square }\end{array}$} \\
\hline & $\mathbf{N}$ & $\%$ & $\mathbf{N}$ & $\%$ & $\mathbf{N}$ & $\%$ & $\mathbf{N}$ & $\%$ & $\mathbf{N}$ & $\%$ & \\
\hline Age (Years) & & & & & & & & & & & $10.02 *$ \\
\hline $18-19$ & 19 & 38 & 59 & 25.1 & 14 & 18.6 & 3 & 11.5 & 95 & 24.6 & \\
\hline $20-21$ & 19 & 38 & 108 & 46 & 35 & 46.7 & 12 & 46.2 & 174 & 45.1 & \\
\hline $20+$ & 12 & 24 & 68 & 28.9 & 26 & 34.7 & 11 & 42.3 & 117 & 30.3 & \\
\hline Housing & & & & & & & & & & & 3.10 \\
\hline Hostels & 35 & 67.3 & 164 & 69.5 & 46 & 61.3 & 21 & 77.8 & 266 & 68.2 & \\
\hline Family house & 17 & 32.7 & 72 & 30.5 & 29 & 38.7 & 6 & 22.2 & 124 & 31.8 & \\
\hline Physical Activity & & & & & & & & & & & 1.52 \\
\hline Yes & 17 & 32.7 & 91 & 38.2 & 31 & 41.3 & 10 & 37 & 149 & 38 & \\
\hline No & 35 & 67.3 & 147 & 61.8 & 44 & 58.7 & 17 & 63 & 243 & 62 & \\
\hline Breakfast intake & & & & & & & & & & & 0.86 \\
\hline Yes & 29 & 55.8 & 127 & 54 & 44 & 59.5 & 14 & 51.9 & 216 & 55.2 & \\
\hline No & 23 & 44.2 & 108 & 46 & 30 & 40.5 & 13 & 48.1 & 177 & 44.8 & \\
\hline $\begin{array}{l}\text { Fast Food } \\
\text { consumption }\end{array}$ & & & & & & & & & & & 2.35 \\
\hline Yes & 21 & 40.4 & 83 & 34.7 & 24 & 32 & 9 & 33.3 & 137 & 34.9 & \\
\hline No & 31 & 59.6 & 156 & 65.3 & 51 & 68 & 18 & 66.7 & 256 & 65.1 & \\
\hline $\begin{array}{l}\text { Number of meals } \\
\text { (per day) }\end{array}$ & & & & & & & & & & & 22.05 \\
\hline $1-2$ & 21 & 41.2 & 136 & 57.6 & 31 & 41.9 & 15 & 55.6 & 203 & 52.3 & \\
\hline 3 & 25 & 49 & 84 & 35.6 & 35 & 47.3 & 11 & 40.7 & 155 & 40 & \\
\hline more than 3 & 5 & 9.8 & 16 & 6.8 & 8 & 10.8 & 1 & 3.7 & 30 & 7.7 & \\
\hline
\end{tabular}

* Significantly different at a level of $\mathrm{P} \leq 0.05$ 
Table 4 indicates the widespread self reported diseases. Results show that the most frequent diseases in descending order of magnitude were anemia (19\%), food allergy (4.9\%), hypertension $(2.8 \%)$ and diabetes $(1 \%)$.

Table 4. The widespread diseases reported by UAEU female students

\begin{tabular}{lcc}
\hline Disease & Number & \% \\
\hline Anemia & 74 & 19 \\
Food allergy & 19 & 4.9 \\
Hypertension & 11 & 2.8 \\
Diabetes & 5 & 1.4 \\
No disease & 279 & 71.9 \\
Total & 388 & 100 \\
\hline
\end{tabular}

Table 5 illustrates the association between food consumption levels and BMI. Results show that $32.6 \%$ of students reported a high consumption of cereals; among them $22 \%$ and $9.4 \%$ were overweight and obese respectively. $46.7 \%$ consumed a high level of fat; among them $18.1 \%$ and $10.4 \%$ were overweight and obese respectively. $27.2 \%$ and $40.8 \%$ of students reported a high consumption of meat and dairy products respectively. It is noted that a high percentage of students consumed a low level of vegetables and fruits (51.5\% and $49.5 \%$ respectively). Results also show that a high percentage of obese and overweight students reported a high consumption of dairy foods, meat and fat and a low consumption of cereals, vegetables and fruits. It is also noted that a high percentage of overweight and obese students reported a high consumption of cereals, vegetables and fruits compared to students with normal weight. We noted a statistically significant association between consumption and BMI groups for cereals and fruits consumption.

\section{Discussion}

The present study was based on a limited sample of United Arab Emirate University female students attending the dietetic clinic and, therefore, results do not necessarily reflect the whole student population trends. Results reported that $19.4 \%$ and $6.7 \%$ of female students were considered overweight and obese respectively, compared with $8 \%$ and $1 \%$ in European countries (Bellisle et al., 1995). The rates reported in this study are much higher than those reported in Europe but they are close to those reported in Arabian Gulf countries. In the same population (UAEU female students), overweight and obesity were found to be $19 \%$ and $9.8 \%$ respectively (Musaiger and Radwan, 1995), and in another study Amine and Samy (1996) reported that $10.7 \%$ and $34.5 \%$ were considered as overweight and obese. Results of obesity reported in the second study are higher than our results. It is noted that in the last study, they did not use BMI to classify students but they used the ratio weight for height percentiles. This can explain the high difference between the two studies. We also reported a high prevalence of underweight $(13 \%)$ especially among young students which confirmed previous results (Musaiger and Radwan, 1995: Amine and Samy, 1996). Musaiger and Radwan reported that 20\% of female students were underweight using BMI $\leq 20$ as a criterion for underweight which is different from our criterion $(\mathrm{BMI} \leq 18.5)$. Other studies in the Arabian Gulf countries reported a high prevalence of overweight and obesity. In Saudia Arabia, Al Nuaim et al., (1996) found that the prevalence of overweight and obesity among female aged over 15 years was $27 \%$ and $24 \%$ 
respectively. In Bahrain, overweight and obesity were found to be $38 \%$ and $16 \%$ respectively (Al Mannai et al., 1996).

Moreover, we found that age was significantly associated with overweight and obesity in agreement with other studies (Al Isa, 1999; Musaiger et al., 1993). Our results confirmed an assumption that underweight and overweight are a common public health problem among this age group. Physical activity and housing were not significantly associated with overweight and obesity, confirming earlier observations on the same population (Amine and Samy, 1996).

Table 5. Association between food consumption level and BMI classes

\begin{tabular}{|c|c|c|c|c|c|c|c|c|c|c|c|}
\hline \multirow{2}{*}{$\begin{array}{l}\text { Nutritional Status } \\
\text { Food groups } \\
\text { ( Level of } \\
\text { consumption) }\end{array}$} & \multicolumn{2}{|c|}{ Underweight } & \multicolumn{2}{|c|}{ Normal } & \multicolumn{2}{|c|}{ Overweight } & \multicolumn{2}{|c|}{ Obese } & \multicolumn{2}{|c|}{ Total } & \multirow[t]{2}{*}{$\begin{array}{c}\text { Chi } \\
\text { square }\end{array}$} \\
\hline & $\mathrm{N}$ & $\%$ & $\mathrm{~N}$ & $\%$ & $\mathrm{~N}$ & $\%$ & $\mathrm{~N}$ & $\%$ & $\mathrm{~N}$ & $\%$ & \\
\hline Cereals & & & & & & & & & & & $6.04 *$ \\
\hline High & 13 & 25 & 74 & 31.5 & 28 & 37.3 & 12 & 44.4 & 127 & 32.6 & \\
\hline Low & 33 & 63.5 & 128 & 54.5 & 37 & 49.3 & 14 & 51.9 & 212 & 54.5 & \\
\hline rarely & 6 & 11.5 & 33 & 14 & 10 & 13.4 & 1 & 3.7 & 50 & 12.9 & \\
\hline Meat & & & & & & & & & & & 3.89 \\
\hline High & 16 & 30.8 & 59 & 25 & 20 & 27 & 11 & 40.7 & 106 & 27.2 & \\
\hline Low & 26 & 50 & 137 & 58.1 & 41 & 55.4 & 12 & 44.4 & 216 & 55.5 & \\
\hline rarely & 10 & 19.2 & 40 & 16.9 & 13 & 17.6 & 4 & 14.8 & 67 & 17.3 & \\
\hline Dairy products & & & & & & & & & & & 3.92 \\
\hline High & 21 & 41.2 & 93 & 39.6 & 32 & 42.7 & 12 & 46.2 & 158 & 40.8 & \\
\hline Low & 20 & 39.2 & 94 & 40 & 34 & 45.3 & 8 & 30.8 & 156 & 40.3 & \\
\hline rarely & 10 & 19.6 & 48 & 20.4 & 9 & 12 & 6 & 23.1 & 73 & 18.9 & \\
\hline Fat & & & & & & & & & & & 9.01 \\
\hline High & 28 & 53.8 & 102 & 43.2 & 33 & 44 & 19 & 70.4 & 182 & 46.7 & \\
\hline Low & 20 & 38.5 & 110 & 46.6 & 32 & 42.7 & 6 & 22.2 & 168 & 43.1 & \\
\hline rarely & 4 & 7.7 & 24 & 10.2 & 10 & 13.3 & 2 & 7.4 & 40 & 10.3 & \\
\hline Vegetables & & & & & & & & & & & 4.38 \\
\hline High & 16 & 30.8 & 70 & 29.7 & 26 & 34.7 & 11 & 40.7 & 123 & 31.5 & \\
\hline Low & 31 & 59.6 & 121 & 51.2 & 37 & 49.3 & 12 & 44.5 & 201 & 51.5 & \\
\hline rarely & 5 & 9.6 & 45 & 19.1 & 12 & 16 & 4 & 14.8 & 66 & 16.9 & \\
\hline Fruit & & & & & & & & & & & $6.92 *$ \\
\hline High & 13 & 25.5 & 59 & 25 & 25 & 33.8 & 12 & 44.4 & 109 & 28.1 & \\
\hline Low & 25 & 49 & 121 & 51.3 & 37 & 50 & 9 & 33.3 & 192 & 49.5 & \\
\hline Rarely & 13 & 25.5 & 56 & 23.7 & 12 & 16.2 & 6 & 22.3 & 87 & 22.4 & \\
\hline
\end{tabular}

*: Significantly different at a level of $\mathrm{P} \leq 0.05$

It is noted that the prevalence of obesity seems to decrease among the UAEU students compared to former studies but the rate of underweight is still high (Musaiger and Radwan, 1995: Amine and Samy, 1996). This can be due to the increase of student's awareness about the body image which has lead to the increase in the rate of underweight. The influence of mass media and TV channels on food habits and food behaviors is very important 
especially among young students. While performing the study, we received many students at our dietetic clinic who were obsessed by losing weight despite the fact that they had a normal weight. This situation is totally different from that reported by Samy and Amine (1996) in their study with the same population. They reported that students with normal weight were seeking counseling to gain weight just to satisfy their husbands who prefer obese women.

Concerning food consumption, we noted a high consumption of meat and fat and a low consumption of cereals, vegetables and fruits. The increase in the proportion of overweight and obese students reporting a high consumption of cereals, vegetables and fruits compared to normal students could be explained by the fact that they became more aware about a healthy diet (rich in cereals, vegetables and fruits) or they have overestimated their consumption. We evaluated the nutritional value of meals distributed in the hostels and we noted a high consumption of starchy products especially rice and bread (15 servings), meat (5-7 servings), and fruits (6 servings), fat ( 7 servings) and low consumption of vegetables (2-3 servings). We should take into consideration that this evaluation concerned the amount distributed for each student but not the quantity really consumed by each student. In addition, many students skipped lunch and most of the time skipped supper. This may be attributed to the timetables as well as the living in hostels. The timetable of students starts from 8 am and may end at $7 \mathrm{pm}$, with several breaks between. This certainly affects the time of consuming meals. The great majority of students are used to having a snack between meals. The components of the snack vary among potato chips, chocolates, soft drinks and sweets. Also, living in the university hostels limits the type and choice of food eaten.

The rate of overweight and obesity in the present study is much more higher than that reported in Europe (Bellisle et al., 1995). These differences could be attributed to many factors and to the differences in the model of acceptable body image between the two regions, being more extreme in Europe than in the Gulf Arabian region, even though food supply is abundant in both regions. There may be a greater pressure to be thin in Europe than in the Gulf region. We did not find significant differences between obese and normal students regarding physical activity. Nevertheless, physical activity may be the foremost among those factors contributing to the level of overweight and obesity among UAEU female students. This can be due to the fact that social and religious norms may prelude female students, especially obese and overweight ones engaging in public sports.

\section{Conclusions}

The prevalence of underweight, overweight and obesity among the United Arab Emirates University was high. This may partly be due to the social and lifestyle of students. There is an urgent need to increase the level of awareness among students of the ill effects of either overweight and obesity or underweight. This requires intervention programs focused on promoting changes in lifestyles, food habits and increasing physical activity. 


\section{Acknowledgement}

The author would like to acknowledge the contribution of senior students who were involved in data collection and data entry and the students who participated in the study. The author also acknowledges Dr Henabulele from the Department of Agribusiness for helping with statistics analysis. The author thanks Dr. Wissam Ibrahim and Dr. Nassar Ibrahim El sawy from the Department of Nutrition and Health for their critical review of the manuscript.

\section{References}

Al Isa, A. N. 1995. Prevalence of obesity among adult Kuwaitis: a cross sectional study. Int. J. Obes 19: 431433.

Al Isa, A. N. 1999. Dietary and socio economic factors associated with obesity among Kuwaiti college men. Br. J. Nutr. 82: 369-374.

Al-Awadi, F. and E. K. Amine. 1989. Overweight and obesity in Kuwait. J. R. Soc health. 109: 175-179

Al-Mahroos, F. and P. M. McKeigue. 1998. High prevalence of diabetes in Bahrainis: Associations with ethnicity and raised plasma cholesterol. Diabetes care. 21: 936-942.

Al-Mahroos, F. J. and A. K. Al-Roomi. 1999. Overweight and obesity in the Arabian Peninsula: an overview. J. R. Soc. Health. 119: 251-3

Al-Mannai, A., J. W. T. Dickerson., J. B. Morgan and H. Khalfan. 1996. Obesity in Bahraini adults. J. R. Soc. Health. 116: 30-32.
Al-Nuaim, A. R., K. Al-Rubeaan, Y. AlMazrou, O. Al-Attas, N. Al-Daghari and T. A. Khoja. 1996. High prevalence of overweight and obesity in Saudi Arabia. Int. J. Obes. 20: 547552.

Al-Shammari, S. A., T. A. Khoja, M. A. Al-Maatouq and L. A. Al-Nuaim. 1994. High prevalence of clinical obesity among Saudi females: a prospective cross-sectional study in the Riyadh region. J. Trop. Med. Hyg. 97: 183-188.

Amine, E. K. and M. Samy. 1996. Obesity among female university students in the United Arab Emirates. J. Roy. Soc. Health. 116: 91-96.

Bellisle, F., M. O. Monneuse, A. Steptoe and J. Wardle. 1995. Weight concerns and eating patterns: a survey of university students in Europe. Int. J. Obes. 19: 723-730.

El- Mugamer, I. T., A. S. Ali-Zayat, M. M. Hossain and R. N. Pugh. 1995. Diabetes, obesity and hypertension in urban and rural people of Bedouin origin in the United Arab Emirates. J. Trop. Med. Hyg. 98: 407-415

Guo, S. S. and W. C. Chumlea. 1999. Tracking of body mass index in children in relation to overweight in adulthood. Am. J. Clin. Nutr 70: $145 \mathrm{~S}-148 \mathrm{~S}$

Moussa, M. A. A., A. A. Shaltout., D. Nkansa-Dwamena., M. Mourad., N. Al-Sheikh., N. Agha and D.O. Galal. 1999. Factors associated with obesity in Kuwait children. Euro. J. Epidemiology. 15: 41-49. 
Emir. J. Agric. Sci. 2003. 15 (2): 42-50

http://www.cfs.uaeu.ac.ae/research/ejas.html

Musaiger, A. O. 1987. The state of food and nutrition in the Arabian Gulf countries. World. Rev. Diet. 54: 1105.

Musaiger, A. O. and M. Al-Ansari. 1992. Factors associated with obesity among women in Bahrain. Int. Qatar Com. Health. Edu. 12: 129-136.

Musaiger, A. O., A. M. Matter., S. A. Lekri and A. R. Mahdi. 1993. Obesity among secondary school students in Bahrain. Nutr. Health. 9: 25-32.

Musaiger, A. O. and H. M. Radwan. 1995. Social and dietary factors associated with obesity in university female students in United Arab Emirates. J. Roy. Soc. Health. 115: 96-99.

Popkin, B. M. 2001. The nutrition transition and obesity in the developing world. J. Nutr. 871S$873 \mathrm{~S}$. 